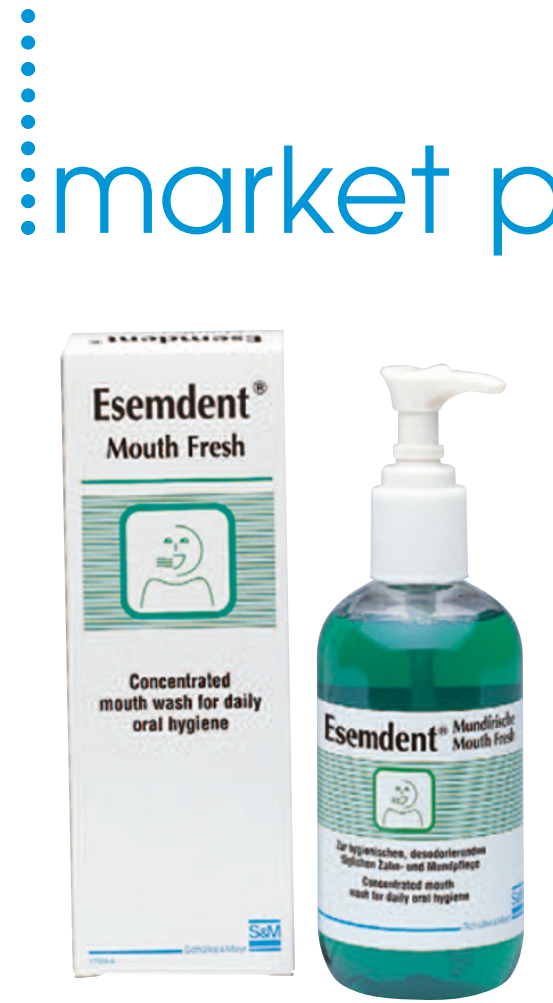

\section{Esemdent for oral hygiene}

Esemdent $^{\circledR}$, from Schulke \& Mayr, is a concentrated mouthwash for hygienic and deodorising rinsing of the oral cavity before, during and after every dental treatment. Esemdent ${ }^{\circledR}$ is ideal for use in daily oral hygiene. Schulke \& Mayr claims that as a result of the cationic substance alexidine, Esemdent ${ }^{\circledR}$ Oral Mouthwash inhibits the growth of opportunistic pathogenic organisms and has bacteriostatic and fungistatic effects.

The manufacturer claims the formulation reduces salivation and nausea when impressions are taken leading to more accurate impressions. For further information visit www.uk.schulke-mayr.com or phone on 01142543500 .

\section{CPD for PCDs}

Eastman CPD is developing courses with verifiable CPD to meet the needs of PCDs once the GDC introduces minimum requirements of continuing professional development (CPD) for PCDs.

Eastman CPD has been delivering CPD courses to PCDs for several years, and already has an established reputation for a wide range of verifiable CPD courses for dentists. The Institute runs established programmes for nurses, hygienists and therapists but opportunities for technicians have been more limited and a programme to serve the needs of technicians when the new PCD legislation comes into force is under development. Study clubs for all of these professional groups are also to be launched.

In all these programmes, Eastman CPD aims to offer a broad range of integrated and comprehensive educational activities and opportunities to encourage, stimulate and support the whole team through structured lifelong learning and personal development plans. In relation to the GDC's proposed registration of PCDs, Eastman CPD aims to offer verifiable CPD for all of the dental team.

When they are introduced by the GDC, the new regulations will put

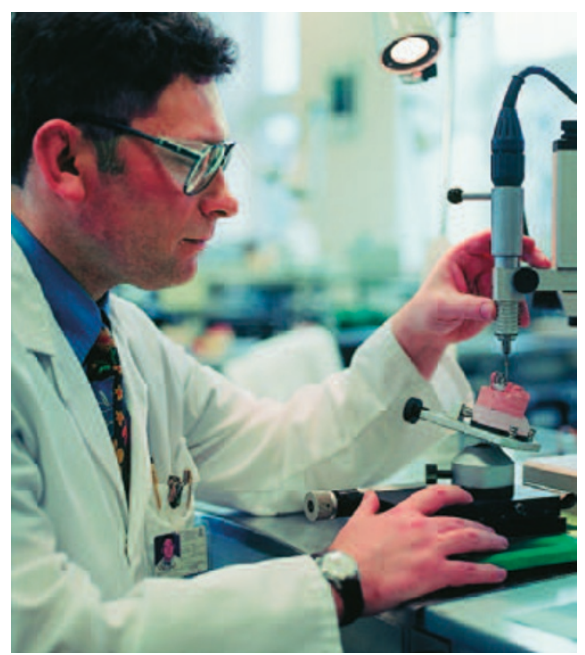

significant demands both on PCDs and course providers alike. As a course provider, Eastman CPD will be continuing its commitment to supporting the entire dental team with its offering of CPD courses. By expanding and developing its activities at this stage, Eastman CPD aims to ensure it will be ready when the changes come into force.

For further information on Eastman CPD contact Ruth Glover, PCD

Programme Co-ordinator, telephone 02079051239 or email

r.glover@eastman.ucl.ac.uk, or visit www.eastman.ucl.ac.uk/cpd.

eastman $1=$

\section{New practice management qualification launched \\ UMD Professional has launched a new practice management qualification designed for dental practice managers. The Level 4 Introductory Diploma in Management is awarded by the Institute of Leadership and Management and has been designed to provide participants with practical management skills as well as a thorough grounding in management theory.}

Marketplace is supplied as a service to the reader and does not imply endorsement by Vital. Normal and prudent research should be exercised before purchase or use of any product.

\section{Admor competition winner}

The winner of the children's table and chair set courtesy of Admor Ltd and Vital Magazine is :-

Dr Sophia Molho, a children's dentist from Dorset. Congratulations Sophia.

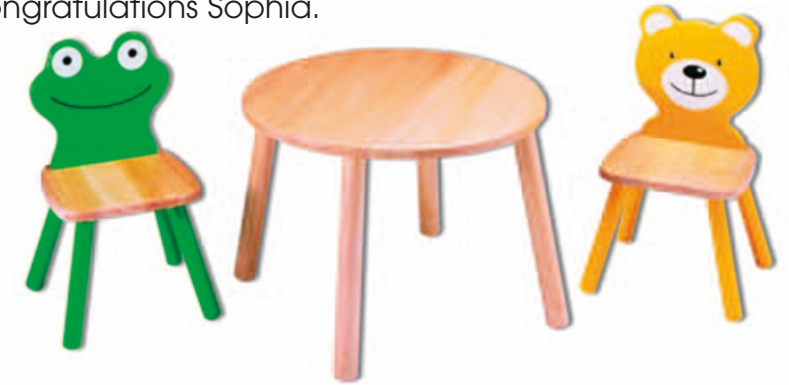

